\title{
Laboratorio intensivo de proyecto arquitectónico Presentación y evaluación del Taller 1:1
}

Arq. Javier Corvalán, Docente invitado FAdu/unl

Arq. Griselda Bertoni, Arq. Eduardo Castellitti, Docentes investigadores fadu/unl

\section{Introducción}

El Laboratorio de Arquitectura inicia sus propuestas de talleres de proyecto desde el año 2000 en Asunción, teniendo continuidad y proyección a nivel internacional en experiencias diversas en escuelas de arquitectura de las ciudades de Panamá, Venecia y Montevideo.

\section{Objetivo}

Hacer reversible el sistema actual de diseño, apuntalado fundamentalmente por el ordenador y el lenguaje digital como representación, por el formato artesanal y la experimentación tridimensional, buscando desarrollar paralelamente los sentidos a través del contacto con la materia y la fenomenología.

\section{Contenido}

El curso intenta definir un concepto de esencialidad con tres elementos básicos, la técnica, el paisaje y la fenomenología; entendiendo que la técnica es el único lenguaje que puede ser verificado y codificado universalmente, el paisaje, sea urbano o rural es el espacio inevitable donde construir y la fenomenología es el campo pendiente por investigar, para incorporar a lo artístico lo funcional en un concepto orgánico. Cada elemento del proyecto será imprescindible desde el punto de vista estructural.

\section{Metodología}

Es un taller práctico con tres tiempos, que busca que el alumno experimente en un tiempo breve el proceso de cambio de estado de una idea a lo material.

Los tiempos se ordenan en etapas lineales de trabajos de campo y seminarios de aproximación, concurso de ideas y construcción real de la idea.

Los ejercicios son grupales, de un total ideal de 80 a 100 alumnos se conforman 20 equipos de 4 o 5 personas, cada alumno debe aportar en la primera jornada un pieza de madera (vigueta) de 4' x 8' x 2m, y depositarla ordenadamente en forma de parrilla superpuesta en el centro del aula en un volumen, de esta manera el estudiante percibirá cualitativamente y cuantitativamente los límites de la escala de materia que transformar.

Los equipos se ordenan en mesas de trabajos alrededor del material mencionado y la escuela debe aportar a cada equipo como material un set de 80 listones a escala 1:10 de los reales, complementando, cada alumno puede contar con un ordenador, lápiz y papel para esquicios o cálculos auxiliares.

La primer etapa siguiente consiste en visitar el área de trabajo, análisis del problema y revelado del paisaje, complementando con sucesivos seminarios y mesas redondas sobre aspectos teóricos y referentes del tema (todas las actividades son colectivas).

Luego se desarrolla la etapa de formulación de ideas. Cada equipo conformado, con el material a escala 1:10 tiene que encontrar en un limite preestablecido de tiempo, la forma estructural que responda a su entender el problema planteado, esta etapa, termina con una evaluación hecha por un jurado de docentes, mediante una exposición colectiva explicada de cada grupo, de esta evaluación, se seleccionara un ganador, que en una tercera etapa, será construido colectivamente como una gran cuadrilla de trabajo de obras en una escala 1:1 con el material depositado inicialmente.

\section{Evaluación}

La evaluación se realiza en la segunda etapa por un sistema de concurso, donde cada grupo expone sus ideas representadas con modelos o maquetas en escala 1:10, que a través de la confrontación multiplica las soluciones al problema común, pero que a través de la crítica de un jurado se determina la solución mas sintética o apropiada. 

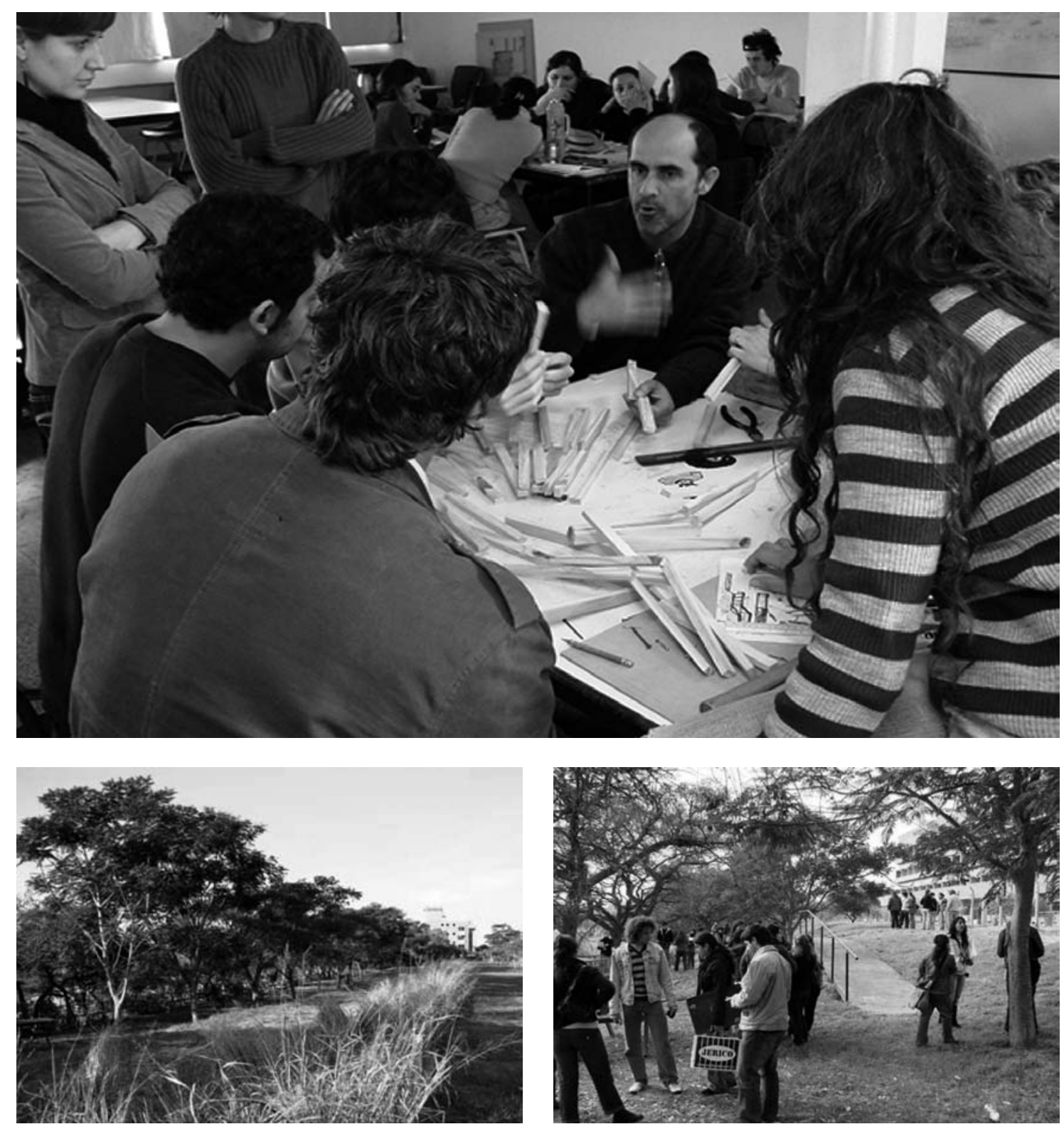

\section{Evaluación del Taller: del Formato}

La propuesta planteada por los coordinadores se llevó adelante de manera efectiva. El trabajo grupal enriqueció la discusión conceptual y metodológica.

La coexistencia en un mismo sitio de trabajo, un aula taller de la FADU, propició el intercambio y la retroalimentación de la experiencia.

En un primer momento la propuesta de trabajo casi artesanal, inmovilizó al grupo. Cabe aclarar que este tipo de tareas no es de práctica habitual (en realidad no se ejercita nunca) ni en los talleres de proyecto ni en los de tecnología.

Luego, el comienzo de algunos grupos en la tarea de procesamiento del material (corte, perforado, vinculaciones de piezas y uniones) activó al resto del taller, que comprendiendo el modo de trabajo replicó esta actividad en el resto de los grupos.

Este hecho confirma el valor de la tarea de grupo, potenciado por la cohabitación en el taller.

\section{De los objetivos y de los contenidos}

Los objetivos eran de diversa índole. Conceptualmente se apeló a los conocimientos de los propios alumnos (temporalmente no hay tiempos pertinentes para el desarrollo de aprendizajes relacionados con contenidos) tensando la reflexión a partir de los cuales se generaron nuevos aprendizajes.

Cabe aclarar que los conceptos de: paisaje y fenomenología son ampliamente desarrollados por los Talleres de Proyecto, las Morfologías, inclusive los Urbanismos, en relación a la técnica, las Tecnologías llevan adelante los contenidos referentes a la técnica.

El diferencial se fundó a partir de la experimentación directa con el material, primero la maqueta de gran escala (1:10) y luego la construcción del modelo 1:1.

Operativamente se logró que la inercia propia del trabajo grupal, sumada a la también propia del taller motiven los aprendizajes y la tarea abordada.

Los grupos dieron respuesta positiva a lo presentado 


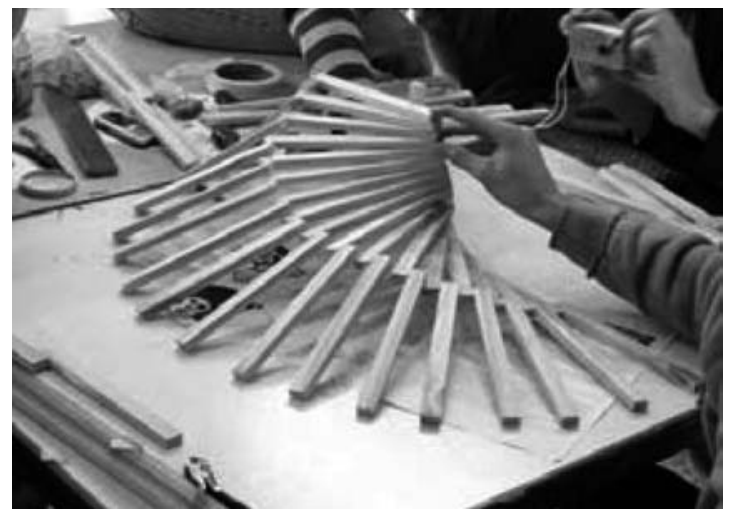

operativamente, desarrollando una tarea inédita en las aulas de la FADU. Se logró el objetivo planteado de la construcción el diseño ganador, como también el involucramiento de gran parte de los alumnos en la tarea colectiva de construcción, no ya de un modelo (maqueta), sino del objeto real a escala real.

\section{Del desarrollo temporal}

El Taller se llevó a cabo en un total de 3 días y medio de jornada completa.

El primer día (a última hora de la tarde) se presentaron los coordinadores externos, se planteó y desarrolló el contenido del taller y se expuso el proyecto para la adecuación del área exterior anexa a la FADU, por ser el lugar del emplazamiento del objeto a diseñar.

El segundo día se visitaron y relevaron los posibles lugares de implantación, para luego comenzar el trabajo de taller. En el ámbito del aula, se inició el trabajo sobre el modelo, con la coordinación de los docentes de Paraguay y los del Taller de Proyecto 5 de la FADU.

Se trabajó durante todo el día, fijándose a última hora de las tareas del día siguiente.

El tercer día se presentaron y expusieron los 22 modelos, para luego ser votados por los docentes y alumnos. Durante la tarde se comenzó la construcción del modelo $1: 1$, terminándose al final del cuarto día con la participación de 25 alumnos aproximadamente. Si bien se podría considerarse a priori que el desarrollo del tiempo

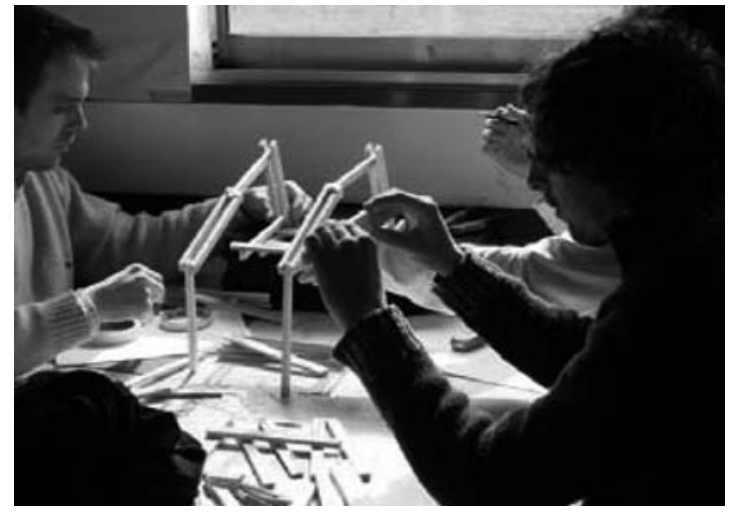

es escaso, la observación de la tarea y la evaluación final demuestran que los alumnos responden adecuadamente en tiempos cortos, de gran concentración, con premisas y objetivos claros.

\section{Del trabajo de los coordinadores}

Los arquitectos de Paraguay tienen experiencias anteriores en la práctica de este taller, por lo tanto su desempeño en la propuesta, el seguimiento y coordinación, es altamente positiva.

Con respecto a los coordinadores de la facultad, se evalúa como satisfactoria la labor desarrollada. En relación a la evaluación de los productos del taller, considero que los docentes de la facultad mostraron una alta predisposición a juzgar el producido a partir de las variables paisajísticas, simbólicas, o formales, dejando a un segundo plano el valor de la propuesta técnica (entendiendo por forma sólo a los atributos de contorno, sintaxis, textura, etc. y no al desarrollo de la materia propuesta).

\section{Del trabajo de los alumnos}

El trabajo de los alumnos, tanto como la predisposición a la tarea fue muy positiva.

Algunos de ellos comenzaron la obra con agrado (trabajar en la facultad no es un hábito muy arraigado en nuestros alumnos de años superiores) y otros se entusiasmaron a medida que entraron en la dinámica del taller. En todos los casos evaluaron positivamente los aprendizajes 


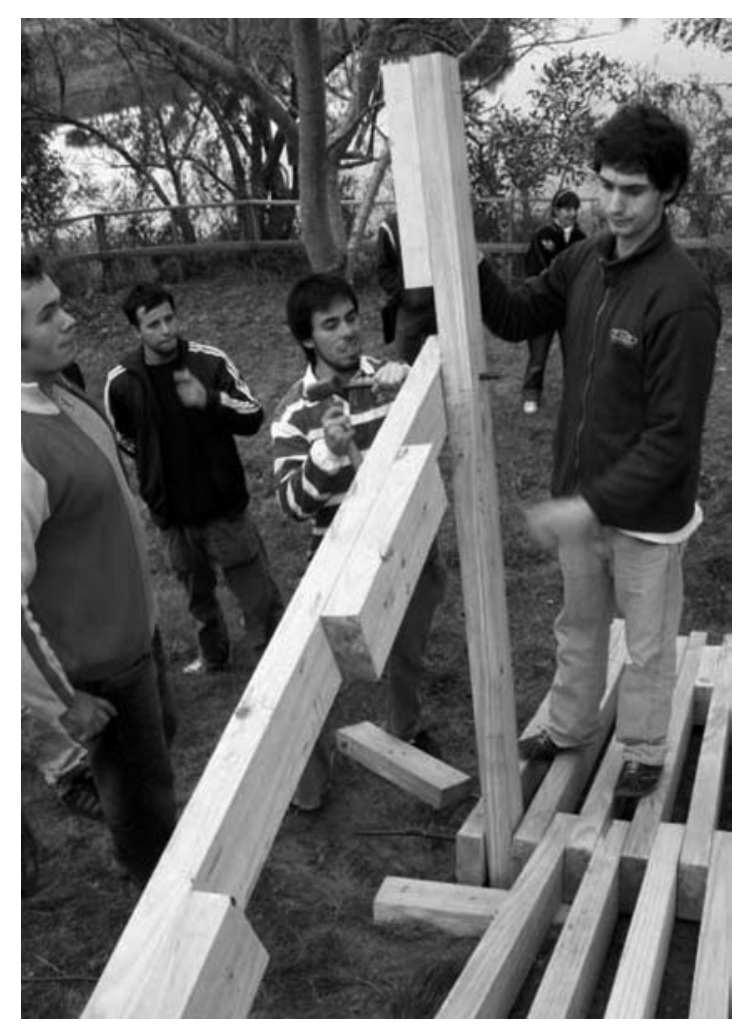

alcanzados (en todos los puntos propuestos) como la capacidad de trabajo en corto tiempo y en el ámbito del taller, inclusive para algunos fue la primera experiencia en relación a herramientas constructivas y resolución real, y el manejo de la técnica apropiada para la construcción de un objeto de uso.

\section{De lo producido}

Los 22 modelos mostraron una adecuada respuesta formal al problema propuesto.

En muy pocos casos los modelos no respondieron técnicamente (se ensamblaron piezas con pegamento sin reflexionar sobre los posibles modos de unión o ensamble real entre piezas). Se hizo evidente el poco conocimiento sobre las posibilidades físicas y estructurales del material de base.

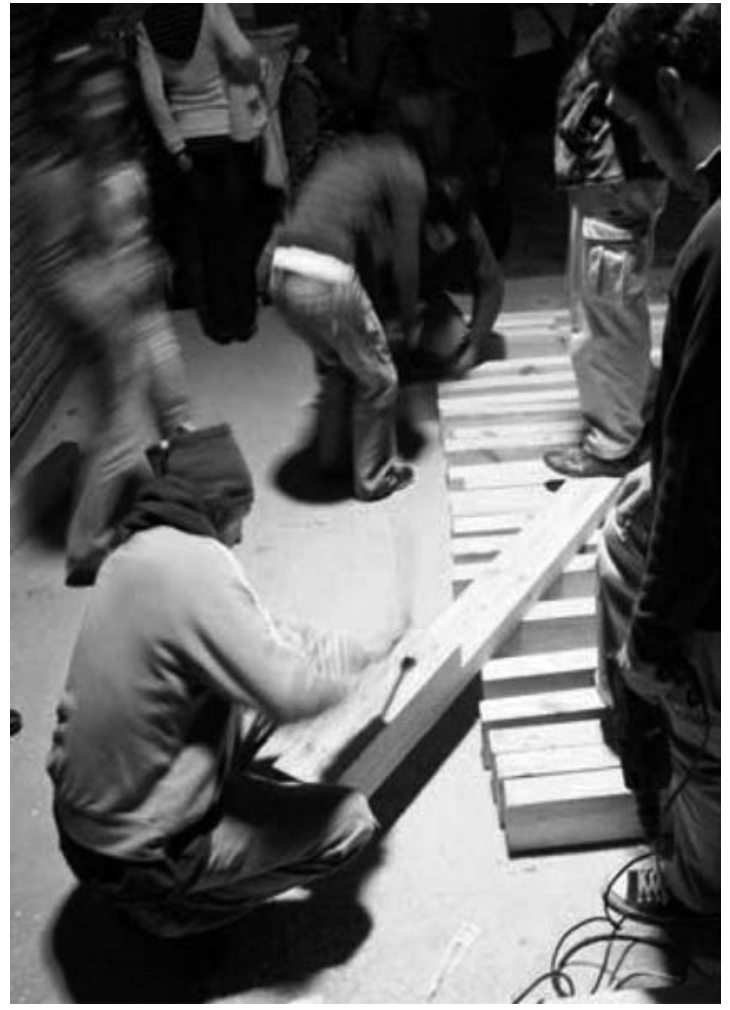

El general los modelos trabajaron sobre formas y técnicas complejas, sin reflexionar sobre los modos de montaje en el sitio de implantación, grandes alturas, necesidad de grúas o aparejos, fundaciones complejas, etc. Esto fue evaluado por los docentes como un impedimento para su elección como modelo a construir.

\section{De la experiencia}

Fue positiva desde todas las perspectivas desarrolladas antes. La experiencia confirma la hipótesis planteada en la investigación sobre el recorte epistemológico del concepto de forma, como así también la ausencia de ámbitos formales de experimentación entre forma, materiales y proyecto en la esfera de la FADU.

\section{en}

Imágenes proporcionadas por los autores. 